\title{
LA ADMINISTRACION DE LOS TERRITORIOS EUROPEOS DURANTE EL PREDOMINIO ESPAÑOL
}

El estudio de la estructura administrativa de los dominios de 1a Corona española en Europa durante los siglos XVI y XVII está por hacer. No pretendemos en estas páginas dar por resueltos sus problemas fundamentales. Basta que consigamos of recer al lector un guión para perfilarlos.

Creemos que una investigación profunda y una labor inteligente y decidicla permitirán señalar en este campo aún virgen no pocos aspectos de gran importancia para la valoración de la obra política de España en su época de predominio.

En nuestra exposición, además, sólo nos referimos a los territorios de Italia y de Flandes (dando a este término la acepción tradicional), y como promesa de lo que esta zona puede dar, vienen también una previa fijación de materias y las referencias precisas a los fenómenos de la incorporación y la legislación. No puede faltar tampoco, aunque vaya truncado por la situación del mundo, un índice biográfico.

\section{I.-TIPOLOGIA Y VINCULO DE LA ORDENACION ESTATAL}

Ante todo, se nos plantea la cuestión de la existencia de una Administración en los dominios europeos de España.

$Y$ al poner ante nosotros este tema, recordemos, de una parte, la trascendencia de cualquier organización administrativa como estructura o forma de un modo de imperar (a nadie le sorprende que digamos cómo a esa administración se liga la persistencia del Imperio de Roma); 'de otro, la necesidad de que la organización administrativa se encuentre vivificada por el elemento jurídico (nadie ignora el papel del derecho en el mantenimiento de las instituciones). 
Mas la cuestión sube de punto en interés si se atiende a un momento tan fundamental como este de la Europa del siglo XVIXVII, sometida a España y a la Casa de Austria.

Sírvanos de oriente un esquema de tipos de administración, montado en contacto con los problemas de su vivificarión interior:

Tendremos así administraciones en las que predomina el elemento estructural y, consecuentemente, lo jurídico; es el caso de Roma y de su Imperio, el "ius latii" y la "Constitutio Antoniniana"; otras en las que su elemento esencial es lo mecánico, el enlace personal y real, con esencia en el séquito: serłáste el caso de las constituciones germánicas, donde la administración se establece sobre los vínculos de los gobernadores con el caudillo; en fin, un tercer tipo en el que destaca el elemento familiar, la sangre, y como vida suya, la dinastía. Y aquí encontramos como ejemplo la administración borgoñona, y en ella la de España bajo los: Habsburgo, como el propio Brandi señalaba (I).

En nuestra dominación extrapeninsular brilla la ley, mas no con el sentido que la dieron los romanos, acaso por el grande influjo de los teólogos y de los poetas (2). No se injertó tampoco el séquito, quizá por las preocupaciones nacionalistas que eliminaron de la Corte del Emperador a determinadas figuras eminentes, príncipes de su Cancillería. Más bien lo que da la tónica es $1_{0}$ dinástico. $\mathrm{Y}$ ante un elemento familiar tan vigoroso sucumben $l a$ ley y la estructura. Que debió ser así nos ayuda a pensarlo lo que sucede cuando falla la dinastía, y el rey, incapaz de mantener una administración de tipo jurídico, o de crearse un séquito que se la lleve adelante, se entrega a un valido, en quien-con más razón que en el rey-se repiten los problemas y acaban por endurecerse y anquilosarse.

La gran importancia que el elemento dinástico tiene se advierte incluso más tarde, en la última crcación habsbúrgica, cuyo Estado plurinacional acaba siendo dirigido por un diplomático, por Metternich.

Para nosotros--en este caso concreto de la Administración de los territorios europeos-es fatal la entrega a las puras razones dinásticas. Como ha notado Rohden (3), por esa culpa "una interrupción de la continuidad dinástica" pudo hacernos descender a

(1) KARL BrandI: Kaiser Karl V. 3.* ed., Munich, 1937, i. pr.

(2) Beneyto: España y el problema de Europa. Madrid, 1942, p. $3^{\prime} 5$.

(3) ROHDEN: Esplendor y ocaso de la diplomacia clásica. Trad. esp. 878 Madrid, 1942, p. 42. 
objeto de la alta política; y ahí está el gran sentido de la guerra de Sucesión.

Otro tema fundamental para comprender la materia es el del vinculo de los territorios extrapeninsulares para con España, silla y espada del E.mperador. ¿Por qué no se unen aquellos Estados sobre una línea federativa o unificadora? Carmelo Viñas dice que por influencia medieval, por reflejar el régimen de la Península (4). Mas no es verdad del todo, aun siéndolo en parte. Que en plena Edad media Aragón sabe ligar los territorios que constituyen su Corona, incluso en el caso concretísimo de Italia-que se repite aquí-. Más bien creo que la endeblez de las estructuras que España establece en la Edad Moderna sobre los territorios que domina son consecuencia del influjo borgoñón y del austríaco. Para afirmarlo así encuentro apoyo en la misma literatura de la época. Campanella subraya este monstruo de nuestra Monarquía calificado por sus muchas cabezas, y Botero mira a España cuando estudia si es mejor el Estado unido o el desunido; sus argumentos dejan ver aspectos muy valiosos, y dan tanta luz que bien merecen un relieve especial. Baste aquí dejar nota cumplida, porque hay más: la falta de unidad en el régimen hispánico es verdadero tópico de la publicística. Un escritor napolitano de principios del XVII, Alberto Pecorelli, se plantea la cuestión de lo que hubiera sucedido si España uniera consigo a Flandes, a Milán, a Nápoles, y aun a las Indias. la China y las Filipinas. ¿Quién se hubiera levantado contra semejante estructura? ¡Qué conde Mauricio ni qué rebelde flamenco! - dice - . Ninguna potencia del mundo hubiera podido enfrentarse con España (5).

(4) Viñas: Imperio y Estado en la España del. Siglo de Oro. "Rev. de la Univ. de Madrid", Letras, I, 1940.

(5) Peccorelli: Il Ré Catholico. I, 10. Ed. Benfrto, Madrid, 1942, p. 5.455.- "Se 'l Potentissimo Ré Catholico havesse unito con la Spagna I'Indie nuove, le vecchie. il Perú, il Brasil, la China, il mondo nuovo, la nuova Spagna, le Filippine, el Mesico, il Regno di Napoli, la Sicilia, Maiorca, Minorca. la Sardegna, li Stato di Milano, la Fiandra, qual potenza del mondo tutto potría resistere o che sollevatione di qual suo stato s'arrogaría di prender l'armi contra questo? O qual ribello flamengo o Conte Mauritio non divenisse timidissimo coniglo? Jo confeso veramente di non intendere ne capire le ragioni contrarie, perche soverchiamente mi sono appoggiato al delto che la virtu unita e piu forte e tanto diverrá maggiore quanto maggiormente s'unisse, non solo d'unione intensiva ma ancor estensiva $\theta$ considerando gli esemplij del istesso Botero che Milano, Fiandra, Napoli e Sicilia si sieno mantenuti per la disunione col concorrere l'uno stato all'altro, anzi questi istessi furono presi molte volte, e con tutto che potessero essere sovenuti dal Ré di Francia, Milano per terra, Napoli $\theta$ :Sicilia per ambedue 379 
Se ve así cómo, desde fuera, tantos estudiosos o sencillamente políticos, subrayaron el talón de Aquiles de nuestra Monarquía. Todos sabían dónde estaba nuestra debilidad y por dónde resistiría poco nuestro dominio. También aquí, en tierras peninsulares, iba advirtiéndose esto-acaso porque estábamos ya en el año terrible de las secesiones, el I640-. Por aquellas calendas escribia Gracián su Político Fernando. Habla allí de la dificultad que supone el gobiernos de Imperios como el de España, en donde climas, lenguas, costumbres y pueblos diferentes iban integrando la Monarquía por reunión de provincias y naciones. Mira Gracián afuera y ve-como antes Eximenis y luego el Conde Duque-aquella Francia, país homogéneo, más trabajado y más vivo (6).

La observación de Gracián es un admirable testimonio de un estado de conciencia que debe estudiarse, porque da nueva luz: a cuestiones que no pueden reducirse por vía lírica en una explicación a posteriori de nuestra propia manera de imperar; la frase es de Fernández de Navarrete, y el concepto, ya lugar común. Ante el hecho histórico, lo que a nosotros importa es la visión coetánea y las iconsecuencias políticas con respecto al Poder, que es el valor político.

\section{II.-Los TópICos}

Y ya que hablamos de tópicos, entremos en examen de algunos que pueden desbrozar nuestro camino. La exposición que pretendemos dar en estas páginas no será en forma alguna valorativa $\mathrm{y}$ ha de alejarse de las zonas dominadas. por la polémica; mas no es posible dejar de aludir a dos lugares comunes muy re-

le parti, come feche in pigliarli tutta volta non si sono potuti mantenere per la potenza di Spagna, segno manifesto che al presente non si conservano per la disunione come dicc. All'incontro, se la Fiandra fosse stata unita con l'altre potenze di Spagna non solo non si sarebbe comperata piu volte con tant'oro e sangue d'infiniti valorosissimi soldati ma voglio dire che non haria havuto ardire di tumultuarsi ne harebbe potuto resistere agli esserciti che si sono levati e di Spagna e d'Italia." .

(6) Baltasar Gracian: El Político Don Fernando el Católico. En "Obras", ed. Madrid, 1720, II, p. 395.- "Ay también grande distancia de fundar un reyno especial y homogéneo dentro de una Provincia al componer un Imperio universal de diversas provincias y regiones... Pero en la Monarquía de España, donde las Provincias son muchas, las Naciones diferentes, las lenguas varias, las inclinaciones opuestas, los climas encontrados, assi como es menester gran capacidad para conservar, assi mucha para unir." 
petidos: la mala administración de los dominios europeos y la absorción de sus cargos por los españoles.

De Flandes dice van Kalken: Los reyes dirigian à sus súbditos mensajes muy hermosos, y colocaban a Bélgica bajo el patrocinio de la Virgen y San José; "pero olvidaban los elementos económicos vitales" (7). Y Badoaro cuenta que en la corte de Felipe II, entre mil quinientas personas, nueve décimas partes eran españoles (8).

Se habla también de preponderancia en los Consejos. Hubo, desde luego, en ellos españoles, y llos naturales de los demás territorios entraban en el Consejo de Guerra, pero no en el de Estado, lo que hace que el veneciano Suriano atribuya al Duque de Parma, Octavio Farnesio, la calificación de "consejo de la plebe" a aquél (9).

Van Kalken exagera la nota al señalar el envío de Gobernadores incapaces y de funcionarios endeudados (IO). Otros autores señalan, sin embargo, cómo descuella el elemento borgoñón e indígena. Recordemos que al iniciar Carlos su ascenso al Imperio, figuraba a su lado Guillermo Du Croy, Señor de Chevrés, como primer consejero y canciller, y que éste era el representante del partido feudal borgoñón (II).

El mismo empuje de l'a etiqueta bor'goñona, por la que se ordena la Corte según la descripción del mencionado Badoaro ( 2 ), es un valioso elemento a tener en cuenta, y en esta zona ha de señalarse que termina imponiéndose en la misma España.

Clertas críticas sobre la Administración, más bien han de entenderse ligadas a la propia decadencia española. Hay, en efecto, una literatura que ha puesto de relieve los defectos de aquella política; por ejemplo: la lentitud de funcionamiento. Así, A1berto Pecorelli recuerda el contraste entre la rápida presentación de la armada de los Caballeros de Malta y los tardíos movimientos de las galeras españolas de Doria, y aun el episodio de aquel caballero cuyo pleito nunca tenía fin y acudió a $\mathrm{Fe}$ lipe II ( I 3).

(7) Van Kalken: La fin du regime espagnol aux Pays-Bas. Bruselas, 1807 , p. 27.

(8) CF. Gachand: Relations des ambassadeurs vénetiens. p. 42.

(9) GaCHARD: Relations. p. 126-127.

(10) VAN KaLKEN: l. C.

(11)! WaLter ANDreas: Die Anfaenge Karls V. Leipzig, 1911.

(12) GF. LEON VAN DER ESSEN : Alexandre Farnese, Prince de Pari:r. Gou,verneur général dles Pa?!s-Bas. Bruselas, 1933, I, p. 27.

(13) Prcorelis : Il Ré Catholico. II, 18 ed. BENEYTo, p. 85-86. 
Hay, evidentemente, algo de todo eso; mas apenas ha sido ahora abierta una etapa de serenidad. Nos encontramos con una extensa literatura, apoyada en razones polémicas antiespañolas. En Flandes están las tesis de la independencia, y la realidad de influjo francoinglés. Fn Italia, el "Risorgimiento", con su plévade de publicaciones tendenciosas. Ya lo van notando algunos investigadores. Así, Mario Viora, Fausto Nicolini, Federico Chabod y Carlos Morandi. Este último declara que se ha ido formando "una más exacta valoración de la edad barroca, de la contrarreforma y del largo período del dominio español en Italia"; "se habla menos-añade (14)-de una decadencia absoluta y genérica, de malgobierno español, de servilismo cerca del extranjero". Y concluye de expresiva manera que todo esto varía "si examinamos las fuerzas positivas y negativas de la Península en su concreta realidad, limpio el terreno de los lugares comunes y de los juicios tradicionales nacidos en el Risorgimiento por obvias razones polémicas" ( I 5 ).

Ias obvias razones polémicas ahí declaradas con fino sentido de la objetividad histórica, han cdlocado a veces obstáculos casi invencibles ante el estudioso de estos problemas. Afinando aun más, Fausto Nicolini habla de ese tópico del "malgoverno". Se trata-dice (16)- del "clesfogue pólítico de los hispanófobos y francófilos, de los austriacantes y autonomistas de los siglos XVI, XVII y XVIII". Son tres centurias de literatura pamfletista, que si vale como juicio o como postura, no puede utilizarse como fuente para la investigación. Un examen crítico de las obras de Pablo Martín Doria (I 7 ) o de Fernando Galiani ( 18 ), ofrece hermoso tema para replantear esta actitud.

$Y$ asi no faltan quienes advierten en la dominación española en Italia incluso méritos de carácter político. Tales, el haber evitado que se cayese bajo el dominio francés o fuese Italia una provincia francesa o franco-otomana, y en fin, el haberla dado

(H's) MaRio VIORA: Sui rapporti fra il Sacro Romano Impero ce l'Italia nci secoli recenti. "Annali triestini di dir., eco. c pol.", X, 1939.

(15) C.ARlo Morand: Gli studi storici in Italia. "Il libro ital. nel mondo". II, 1941, 4, p. 20.

(16) Fausto Nicorini: Aspetti della rita italospagnuola nel Cinque $e$ Seicento. Nápoles, 1940. p. 236-240. esp. i. pr.

(17) PAOLO MARTIN DORIA: (1664-1746) escribe su Relazione dello stato politico, economico $c$ civile del regno di Napoli nel tempo ch'è stato governato dagli spagnuoli. Ed. M. SCHIPA, "Arch. stor. prov. nap.", XXIV, 1889.

(18) Ferdinando Galiani (1728-1782) estudia en su Moneta (1751. 882 Ed. Nicolin. Bari, 1916) la época española, como triste paréntesis. 
en I734 la posibilidad del impulso nacional mediante la proclamación de ila independencia de Sicilia, cedida por Felipe $\mathrm{V}$ a su hijo Carlos (19). Arrancan de ahí la idea de la reconquista hispanoborbónica de Nápoles y el plan de constitución de un Confederación presidida por el Papa (20).

De esta manera, la versión "risorgentística" situada por Manzoni en sus Novios, aparece como una caricatura, obra de aquel antihistórico iluminismo setecentista (2I). A su lado cae el mito del "malgoverno" con el otro mito-igualmente insostenible-de la anterior y edénica felicidad (22). Como cae el término mismo del "predominio straniero". Por :lo pronto, y sin ir a apurar el capítulo de la participación de los naturales, ya Mario Viora ha sacado afuera un largo período, el del Imperio: la intervención de Carlos V como Emperador en Milán, por ejemplo, no es predominio de potencia extranjera, sino cumplimiento de tareas imperiales en las que Italia participa (23).

\section{III.-LA INCORPORACION}

Para enfocar el régimen a que se someten los territorios europeos bajo la Administración española, hay que empezar planteando las peculiaridades de su forma de incorporación. Y con ello va el viejo problema de si deben hacerse o no modificaciones en el "regnum" que se incorpora a otro cetro. La controversia sobre las leyes, tan viva en el sigla XVIT (24), se endaza a la tradición medieval de respeto al derecho viejo (25), y con el problema que señala la Publicística con el sabido debate de si el rey nuevo debe establecer novedad (26). Es dentro de esta atmósfera dónde y cómo conviene situar la actitud del gobierno español, para advertir de qué manera las formas y las ideas se relaciona-

(19) Nicolini: Aspetti, p. 184.

(120) CF. NICOLINI: Sulla riconquesta ispanoborbonica del Regno di Napoli. "Arch. stor. ital", Florencia; 1931.

(21). Sobre la versión "risorgentística" y manzoniana, Nicolins, Aspetti, página 185.

(22) CF. Nicolini: Aspetti, p. 237.

(23) VIORA: Sui rapporti, 1. c.

(24) Recuérdese el pasaje del discurso de Felipe II ante las Cortes do T'oledo: "Leyes pocas y que se cumplan." Adviértase la postura do los legistas en López Madera, con su teoría de la necesidad de leyes nuovas.

(25) Sobre el tema del respeto al derecho viejo, documentos interesantes en BENEyTo, Textos políticos españoles dẹ la Baja Edad Media. Madrid, 1944 .

(26) Peconelli: Il Ré Catholico. II, 31. Ed. Beneyto, p. 95-96. 
ban entonces. Sólo así podrá juzgarse con criterio histórico esta importantísima etapa de la vida europea.

$\mathrm{Y}$ como antecedente, quede reseñada la adquisición de estos territorios, porque también por estas raíces se mueven las razones.

Italia es para la Corona española, y en su mayor parte, una herencia de la Corona aragonesa. Sicilia recibe a Pedro III, por vínculo familiar, y en virtud de aclamación. Jaime II acude a Cerdeña, por haber sido investido de la potestad correspondiente por el Pontífice. Nápoles es herencia y esfuerzo de Alfonso.V. Al lado de estas zonas está Milán, feudo del Imperio, como aportación imperial habsbúrgica, ligada a la Corona de Hierro de Mónza, impuesta a Carlos, en la víspera de la gran coronación boloñesa. La tradición es larga. Pedro III, reivindicaba ila herencia de los Staufen, tras la muerte de Federico II (1250), por estar casado con la hija de Manfredo, nieta del Emperador, y sin que faltasen otros lazos, como el de aquella Constanza, hija de Pedro II, que muere en Catania, en 1222 (27). Mas a Pedro III se le aclama, según las crónicas de Bartolomé de Neocastro y Nicolás Specialis (28). EI vínculo permanece en la Casa aragonesa, con Jaime. II, cuya hija Isabel, casa con Federico de Austria, nieta deĺ rey de Nápoles, Carlos de Anjou, con cuya hija está casado Jaime.

Cuando Alfonso V va a Nápoles, le llama la reina Juana; mas cuando ha ganado el reino es con la entrada de I442. Fernando el Católico, piensa en Nápoles, cuando trata con Luis XII, en noviembre de I500, y por ahí le llega à Carlos el Emperador toda una línea hermosamente rellatada por el obispo Ruiz de la Mota, en las Cortes de La Coruña: "que si el Rey Don Alonso de Aragón no salier'a de España, la Corona Real no poseyera el reino de Nápoles con tan "justos títullos como agora los posee"... (29). Flandes, viene como herencia borgoñona. Felipe el Hermoso había casado con Juana, hija de los Reyes Católicos. Con el reinado de Carlos $\mathrm{V}$, la situación y el vínculo cobran tanta fuerza que de Flandes y Borgoña acuden muchos de su séquito.

Más expresivo que todas las aportaciones es el hecho de la persistencia de la fidelidad de los belgas a la metrópoli española, per-

(27) M. Schippa: Sicilia $c$ Italia sotto Federico II di Suevia. "Arch. stor. prov. nap.", N. S., XIV, 1928, p. 5-113.

(28) Schippa, l. c. p. 25. Estos aspectos en Montero Diaz, Semblanza italiana de Pedro III. Murcia, 1941.

884 el. problema de Europa, p. 161.

(29) El pasaje del discurso de Ruiz de la Mota, en BENEyTo, España y 
sistencia que se mantiene en el curso de siglo XVII, y que para van "Kalken "tiene algo de sorprendente, y ha sido puesta en duda por los historiadores contemporáneos". (30). De Itailia hay también textos valiosos. Uno de Pecorelli, a principios del siglo XVII, alude al régimen de España, diciendo que si lo conociesen lios demás pueblos todos quisieran ser súbditos de nuestro rey (31). Es más-ya lo hemos notado-, la actitud de la Monarquía española preparó la independencia italiana (32).

\section{IV.-Histortografía y FUExtes}

Cuanto llevamos dicho hace ver el enorme interés que tiene desde cualquier punto de vista, el estudio, la administración de aquellos territorios. Las ideas que rigen y las formas que se implantan, merecen una detenida investigación. Advirtamos como dificultades iniciales para abordar este estudio: el carácter polémico de la primera literatura, y el despego de los españoles por la materia. Tenemos una historia como la tendrían los romanos si los cartagineses hubiesen vencido, y no hacemos nada por conocer en su exactitud fenómenos que tan vigorosamente pesan sobre la historia y la psicdlogía de nuestro pueblo.

Aunque algún autor belga declare que "la historia de las instituciones de los Países Bajos está ya hecha" (33), no es posible admitir' que esto quede resuelto sobre los libros de Neny, $M e$ moires historiques et politiques des Pays Bas antrichiens, Bruselas, I785, Steur, Precis historique de l'etat politique des Pays Bas, Bruselas, 1828, Gachard, Documents inedits, Bruselas, I83I, y La Belgique sous Philippe $V$, Bruselas 1867 , y Poulet, Les constitutious nationales belges de l'ancien regimen, Bruselas, I875. I-a realidad es que, a pesar de lo que estos libros significan, la historia de las instituciones espera todavía la explotaciôn científica del riquísimo venero de los archivos. Y si eso sucede con obras del siglo pasado, ¿qué puede decirse de las anteriores? Salazar, se li-

(30) Van Kalien, o. c. p. 68. Contra A. V. Ruville, Preuss, Wilhelm von England und das Haus Wittclsbarh im Zeitalter der spanischen Erbfolgefrage. Breslau, 1905, y contestando a aquél en la "Deutsche Literaturzeitung", $\mathrm{X}, 1906$.

(31) Pecorelli: Il Ré Calholico. J. 2. Ed. Beneyto. p. 34._-"Degni veramente solo di Potentissimo Christianissimo e Catholico Ré nostro, che so gli sudditi altrui provassero il modo de suoi governi como facciamo noi altri, dishabitavano le patrie per venire ad habitare cotali Staiti."

(32) Nicolini, l. c.

(33) VAN KaLkEN: La fin du régime espagnol., p. 60. 
mita a describir los Estados de Flandes e Italia, y la genealogía de sus príncipes (34). Guicciardini, recoge mapas y hace et "retrato natural" de las principales tierras, con algo de lo que cree "generale reggimento" (35). El propio van Kalken, de quien es aquella primera afirmación, reconoce que nuestro dominio "ha. sido apreciado muy diferentemente, y a menudo, muy falsamente" (36). En efecto van Kailken ha intentado un juicio imparcial, pero se ocupa solamente del último período, e incluso cae en las posiciones tópicas, sobre las que no resuelve nada.

En fin, los dos aspectos van siendo vencidos; la literatura extranjera pierde carácter polémico, y los españoles toman afición a estas cuestiones.

A título de orientación y sin la pretensión, que sería temeraria, de ofrecer un catálogo exhaustivo, para dar una visión del panorama, señalamos aquí los trabajos que consideramos más útiles.

Aparte de algunas elaboraciones de conjunto, como la de $\mathrm{Vi-}$ ñas (37), y la mía (38), pueden servir para Italia, y a título de antecedente, mi trabajo sobre el derecho catalán (39), la biografía de Ambrosio Spínola de Rodríguez Villa (40) y las colecciones de correspondencia preparadas por Pacheco, Serrano y Pérez Bustamante (4I). El libro de Picatoste (42), con título tan sugestivo, es obra declamatoria e inservible. Ofrece interesantes aportaciones para juzgar la política española en Italia, II Re Catholico, del napolitano A.tberto Pecorelli (43).

(34) Salazar: Monarquía de España, tomo scgrundo.

(36) VAN KaLkEN: o. c., p. 1.

(36) Van Kalken, oc. c., p. 1.

(37) VIÑAS: Imperio y Estado en la España del Siglo de Oro. "Rev. Univ. de Madrid", Letras. I, 1940.

(38) BENEYTo: España y el problemi de Enıropa. Madrid, 1942.

(39) BENEYTO: Il diritto catalano in Ilalia. "Riv stor. dir. ital.", VI, 1933.

(40) Rodríguez Vir.la: Ambrosio Spinola, primcr marqués de los Balbases. Madrid, 1905.

(41) PaCheco Y DE Leiva: La politica española en Italia. (Correspondencia del Aliad de Nájera.) Madrid, 1919; L. Serrano: Correspondencia diplomática entre España y la Santa Sede. Madrid, 1914; Pérez Bustamante: La correspondencia diplomática entre los Duques de Parma $y$ sus agentes o embajadores en la Corte de Madrid durante los siglos XVI, XVII y XVIII. Madrid, 1934.

(42) PICATos'e: Los españoles en Italia. Madrid, 1887. Lleva el título general de "Estudios sobre la grandeza y la decadencia de España"; dos volúmenes sobre "Los españoles" y un tercero sobre "El ejército español en Italia".

(43) Ṕeconelli : Il Ré Catholico, ed. y estudio de J. Beneyto Perez. "Publicaciones del Seminario de Historia de las doctrinas políticas", I, Madrid, 1942.) 
Los italianos se han preocupado mucho últimamente de trabajar en estas materias, y así deben considerarse los estudios de Monti y de Nicolini (44), la exposición del reinado de Federico II, hecha por Schippa (45), y las relaciones de embajadores publicadas por Morandi (46), Giardina ha estudiado la organización de los Consejos supremos (47).

Desde un punto de vista geográfico podemos ir clasificando, también, las aportaciones monográficas. Sobre Cerdeña es muy abundante la producción italiana-lo mismo que sobre Sicilia-, por la razón que ya apuntamos (48), de los escalafones universitarios. Sobre Cerdeña, Besta, of reció una visión de conjunto muy valiosa (49), y Antonio Era ha publicado pragmáticas y documentos (50). La historia de las instituciones cuenta con aportaciones muy valiosas para su estudio. Además del libro de Solmi (5I), deben conocerse los de Marongiu, Pallone, Vaccara y Viora, que respectivamente versan sobre los Parlamentos, los Virreyes, la Real Audiencia y el Regente de la Cancillería (52). Sobre Córcega, tan solamente es útil el trabajo de Marongiu, en torno a la actitud de la Corona aragonesa (53). Sobre Sicilia sc poseen, la vieja "descripción" de Bern (54), y la historia

(4) Mont: Dagli Aragonesi agli Austriaci, Studi d'istoria meridionale, 'I lani, 1936; -Dai Normanni agli Aragonesi, Trani, 1936. Nicolini: Aspetli della vita italospagmuola nel 500 e 600, Nápoles, 1934; -Peste e untori nei "promesi sposi" e nella realtá storica. Bari, 1937.

(45) Schippa: Sicilia e Italia sotio Federico II di Suevia. "Arch. stor. prov. nap.", N. S., XIV, 1928.

(46) MORANDI: Relazioni d'ambasciatori sabaudi, genovesi e vencti (16901713). Bolonia, 1935 .

(47) GiaRdina: Sul governo centrale syagmuolo e sull'anno di fondazione del supremo Consiglio d'Italia. "Arch. stor. per la Sic.", IV, 1938; -Il supremo Consiglio d'Italia. Palermo, 1934.

(18) Cr. PRnFyto: Il diritto calalano. "Riv. stor. dir. ital.", 1833.

('i9) Besta: La Saricgna medievale. Palermo, 1908.

(50) ERA: Uno prammatica inedita di Alfonso $V$ d'Aragona relativa al' elezione del Consiglio civico di Cagliari. "Studi sassaresi", V, 1926; -Tre secoli di vita cittadina (1479-1720) (Documentos del Municipio de Caller.) Caller, 1937.

(51) SolmI: Studi storico sulle istituzioni della Sardegna nel medioevo. Ciller, 1917. (52) MAnONGIU : I Parlamenti di Sardégna nella storia en el diritto júbblico comparato. Roma, 1932; - Il Reggente la R. Cancelleria, primo minis tro del goberno viccregio in Sardegna. "Riv. stor. dir. ital.", V. 1932: Paldone: Ricerche storico-!iuridiche sul Viceré di Sardcyna, "Studi sassaresi", X, 1930; VACCARA: La Reale Udienza. Caller, 192S; VIORA: Sui Vicerè di Sicilia e di Sardegna. "R!v. stor. dir. ital.", III, 1930.

(53) Marongiu: La Corona diaragona e il regno di Corsica. "Arch. sto:. per la Corsica", XI. 1935.

(54) BERN: Descrittione e relatione del governo di stato $e$ guerra nel ficqno di Sicilia. Palermo, 1694. 
cronológica" de Blasi (55). El gobierno español en general ha sido enjuiciado por Arenaprimo (56), mientras Capasso lo hace del virreinado de Don Fernando Gonzaga (57). La influencia del derecho español en las instituciones de Sicilia ha sido objeto de dos monografías de Luigi Genuardi (58). No deben olvidarse los trabajos de La Lumia (59), La Mantía (60) y Palmieri (6I). La historia de las formas políticas ha encontrado eficaz impulso en Camillo Giardina, autor de un estudio sobre institución del virrey de Sicilia (62), Genuardi, que ha historiado el Municipio de Palermo (63), Calisse, que escribió una historia del Parlamento siciliano (64), y Di Martino, investigador de! sistema tributario establecido por la Corona aragonesa $\left(6_{5}\right)$. Sobre Nápoles, poseemos las aportaciones documentales e histórico-descriptivas de Capaccio y Parrino (66), el "Codice aragonese" (67), y algunas instrucciones y cartas, así como las cédulas de tesorería (68), y una vida del famoso virrey Don Pedro de Toledo (69). También existe un estudio sobre el virrei-

(55) BLASI: Storia cronologica dei Vicerè di Sicilia. Palermo, 1842.

(56) ARENAPRIMO: Il governo spagnuolo in Sicilia nei secoli XVI e XVII. Messina, 1892.

(57) Capasso: $1 l$ governo di Don Ferrante Gonzaga in Sicilia (1535-1546). "Arch. stor. siciliano", N. S., XXX-XXXI, 1905-1906.

(58) GENuARd : La influcncia del derecho espiañol en las instituciones publicas y privadas de Sicilia. "An. hist. der. esp.", IV, 1928; -Il diritto publico spagnuolo in Sicilia, "Riv. stor. dir. ital.", VI, 1933.

(59) I.A LumiA: La Sicilia sotto Carlo V, 1862.

(60) LA MANTIA: L'ordinamento intemo del Regno di Sicilia sotto gli Aragoncsi (1282-1409). Palermo, 1934.

(61) PALMIERI: Saggio storico e politico sulla costituzione del regno di Sicilia fino al 1816. Palermo, 1818.

(62) Giardina: L'Istituto.del Vicèrè di Sicilia. Palermo, 1930.

(63), Genuardi: Il Comune di Palermo sotto il dominio spagnuolo. Palẹrmo. 1891 .

(64) CaLisse : Storia del Parlamento in Sicilia. Turín, 1887.

(65) Di Martino: Il sistema tributario dégli Aragonesi in Sicilia (12821516). "Arch. stor. per la Sic.", IV, 1938.

(66) Capaccio: Descrizione di Papoli nei principii del secolo XVII. EN. B. Capasso; PaRrino: Teatro eroico e politico dei governi de viceregnali, Nápoles, 1861-1863.

(67) Tirinchera: Codice aragonese. Nápoles, 1866.

(68) Lettere e istruzioni dei Ré Aragonesi, ed. Albino, Nípoles, 1769; Cione: Una lettera poco nota di A. Catone nella congiura dei Baroni, "Riv. stor. itl.", 1941. BARONE: Le cedole di tesoreria del 1460 al 1504. "Arch. stor. nap.", IX.

888 (69) MIccio: Vita di Don Pietro di Troledo. "Arch. stor. ital.", XI, 1842. 
nado del Duque de Alcalá ( 70$)$. Ia bibliografía moderna sobre instituciones se concreta a trabajos sobre la Universidad (7I), Ía política de abastecimientos (72) y el Parlamento (73). En cuanto a Milán y la Lombardía, sobre el libro de Pozzi (74), los de Chabod (75), Barbieri (76), Casadei (77) y Morandi (78), plantean y resuelven problemas de carácter general. La administración pública ocupó a Visconti (79), mien'tras el fundamental instituto del Senado suscita una propia bibliografía (8o).

La literatura en torno a Flandes tiene también muy poca participación de españoles. De la "Historia" de Barrantes Maldonado (8I) hasta hoy, apenas pueden citarse los estudios de Barado y de Morales Oliver sobre Requesens y Arias Montano (82). De parte belga los trabajos abundan, sin que falten otras aportaciones, como la de Hauser, respecto a la cesión de

(70) Mauno: Il virereame di N'apoli al tempo del Duca d'Alcalá. Pessaro, 1914.

(71) Contese: Lo studio di Napoí nell'età spagnuola. Nápoles, 1924.

(72) Coniglio: Note sulla storia delia politica annonaria dei Vicerè spagnuoli a Napoli. "Arch. stor. nap.", N. S. XXVII, 1942.

(73) 'CROCE: Il Parlamenti napoletani sotto la dominazione spagnuola. Nápóles, 1937.

(74): PozzI : Il governo degli spagnuoli in Lombardia. Como, 1893.

(75) 'CHABoD: Lo Stato di Milano nell'Impero di Carlo V, Roma, 1934; Per la storia religiosa dello Stato di Milaro durante il dominio di Carlo $V$, Milán, 1940 (n. b. i. ext.o de CASADEr, "Riv. stor. ital.", 1941).

(76) Barbien'l: Economía e Politica nel Ducato di Milano, 1386-1535. Milán, 1938.

(77) CASADEI: Per la storia religiosa dello Stato di Milano durante il dominio di Carlo V. "Riv. stor. ital.", LVIII, 1941.

(78) Morand: Considerazioni sul dominio spagnuolo in Lombardia. "Ann. R. Scula Normale Superiore di Pisa", VII, 1938; -Lo Stato di Milano e la politica di Vittorio 'Amedleo II, 1690-1696. "Ann. R. Ist. stor. ital. per l'Etá Moderna". Bolonia. 1939.

(79) Viscons1: La publica Amministrazione nello Stato milanese durante il predominio straniero. Roma, 1913.

(80) Crespi: Dal Senato di Milano al tempo della dominazione spagnuola. "Arch stor. Iombardo", 1899; Del Giunice: I Consigli Ducali $e$ il Senato di Milano, Milán, 1899; Molteni: Del Scnato di Milano. Milán, 1897; VIANEJLo: Il Senato di Milano. "Arch. stor. lomb.", LXII, 1935. Más recientemente el P. José Marfa MARCH, S. I., ha dado algunas referencias al gobierno de la Lombardía en su preciosa y documentada monografia El comendador de Castilla Don Luis de Requeséns en el, Gobierno de Milán, 1571-1573. Madrid, 19 亿3.

(81) Barrantes y Maldonado: Historia de los Condes de Flandes, 1566.

(82) BARADO Y FONT: Don Luis de Requcséris y la política española en los Países Bajos, Madrid, 1906; Monales Ouiver: Arias Montano y la política de Felipe II en Flandes, Madrid, 1927. 
Borgoña (83), etc. Los estudios de conjunto versan sobre distintas épocas: Carlos V (84), Felipe V (85), Alejandro Farnesio (86)... Especial mención merece el ya citado libro de van Kalken (87). Aportan valiosos datos las monografías de von Goes y Gossard sobre españoles y flamencos (88); pero, por desgracia, faltan estudios sobre las formas políticas, predominando la fliteratura relacionada con las luchas religiosas, convertidas en tejido esencial de esta época (89). Los aspectos institucionales apenas cuentan con los trabajos de Pirenne, Steuer. y Poulet (90). Existe una historia del Consejo privado (91), y una monografía sobre la reunión del Parlamento en 1534-35 (92). Por lo demás, uno de los temas tratados con mayor amplitud es el de la reforma carlina de la beneficencia, tema que se relaciona con la dostrina de Juan Luis Vives, expuesta en su libro "De subventione pauperum", dedicado a las autoridades de Bru-

(83) HAUSER: Le traité de Madrid et la cesión de la Bourgogne a Charlcs Quint. París. 1912.

(84) Juste: Les Pays-Bas sous Charles Quint (Vie de Marie d'Hongrie, tirée des Papiers d'Etat). Brusalas, 1855; Fredenicn: De Nederlanden and $\mathrm{r}$. Keizer Karel, Gante, 1885; HeNNE: Histoire de Regne de Charles Quint en Belgique, Bruselas, 1858-1860; THEISSEN : De regecring van Karel $V$ in noordelijke Nederlanden. Amsterdam, 1912.

(85): GaGHARD: La Belgique sous Philippe V. Bruselas, 1867.

(86) VAN DER ESSEN : Alexandre Farnese, Prince de Parme, Gouverneur général des Pays-Bas (1545-1592), Bruselas, 1933-1937; FEA: Alessandro Farnese, Florencia, 1886.

(87) Van KaLKEN: La fin du regime espagnol aux Pays-Bas. Bruselas 1907 .

(88) VAN GoES: L'intervention des espagnols dans l'adminstration fiscale; Gossard: Espagnols et Flamands au XVI e siècle, Bruselas, 1906.

(89) KaLKOFF: Die Anfaenge der Gegenreformation in den Niederlanden, "Arch. 1. Reformsgesch.", I; Lefevre: L'intervention du Duc de Lerme dans les affaires des Pays-Bas (1598-1618), (Rev. belge de phil. et d'hist., XVII. 1939, LONCHAY: La rivalité de la France et de l'Espagne aux Pays-Bas (16351700), Bruselas, 1896; MARKs: Studien zur Geschichte des niederlaendischer Aufstandes, Leipzig, 1902; NAMEcke: La regne de Philippe II et la lutte religieuse dans les Pays-Bas; PIRENNE: La politique de Gérard de Groesbeck, prince-éveque de Liège pendant le Gouvernement de Don Juan d'Autriche, "Travaux de l'Inst. Paul Fréderich, Univ. de Liège", II, 1; STrada: De bello Belgico, Viena 1754.

(90) PIP.ENNE: Die Entstehung und die Verfassung des burgundischen Reiches im XV und XVI Jahrh., 1909; STEuer: Precis historique de liétat politique des Pays-Bas, Bruselas, 1828; PoulET: Les constitutions nationales. bclges de l'ancien regime, Bruselas, 1875.

(91) AlmXandre: Histoire du Conseil privé. "Mem. Acad. R. de Belgique", LII.

(192) VAN DBR Essen: Les Stats géneraux de 1534-1535. "Mél. Ch. Moel890 ler". París, 1914. 
jas (93). No faltan, de otro lado trabajos sobre temas militares (94).

Bien podria decirse que lo que caracteriza la literatura flamenca sobre la dominación española es la abundancia de documentos-que hace prever un estudio cada vez más objetivo y eficiente. Han sido publicados, la correspondencia de Margarita de Parma (95), la de Felipe II (96), la de la Corte española (97), etc. Gachard, no sólo ha dado a -luz importantes documentos, sins que ha rebasado con propósito orientador, los fondos de las bibliotecas españolas (98). La "Societé d'histoire de Belgique" ha hecho imprimir textos interesantes en su Colección de Memorias (99), mientras la Comisión Real de Legislación histórica y el Ministerio de Justicia han editado antigiuas ordenanzas (IOo). España ha colaborado a estos esfuerzos y en ese sentido debe señalarse el Inventario editado por $\mathrm{Paz}$ (IOI).

Sobre el Franco-Condado la literatura es muy pobre. Apenas el libro de Febvre (102), autor también de una historia general de aquella región.

Interesa sin duda a España el trabajo en esta amplísima zona. Los archivos y las bibliotecas of recen material al estudioso. Sencillamente, a guisa incitativa, quiero señalar algo de lo que

(93) F.HRLE: Die Armenordnungen von Nuerberg und von Ypern. "Hist. Jahrb", IX, 1888; Nol.F: La réforme de la bienfaissance publique à Yprès a XVI è siècle, "Travaux Fac. Lettres de Gand", XLV, 1915; WInckelmanN: Leber die aeltesten Armenordnungen der Reformationszeit, "Hist. Vierteljahrsch". XVII, 1914-1915; BoNENFAN'r: La réforme de la bienfaissance publique aux Pays-Bas sous Charles Quint, "Rev. belge de phil. et' d'hist.", 1926-1927.

(94) ThERLinden: La siéqe d'Anvers par Alexandre Farnese, Bruselas, 1015; Von Koss: Die Schlachten bei S. Quentin und Gravelinas, Eine Studium ueber spanische Infanterie, "Hist. Studien", 118.

(95) REIFfenbera: Correspondence dr, Marguerite d'Autriche, Duchese de Parme, avee Philippe II, Bruselas, 1842: VAN DEN BERGH: Correspondcnce de Marguerite d'Autriche, Leyda, 1845-1847.

(96) G.CHARD: Correspondence de Philippe II sur les affaires des PaysBas, Bruselas, 1848-1879.

(97) Correspondence de la Cour d'Espagne sur les affaires dcs Pays-Bas. Ed. Cuvelier y Lefevre, Bruselas, 1937.

(98) GACHARD: Documents inedits, Bruselas, 1831; -Les biblioteques de. Madrid et de l'Escurial. Notices et extraits des mss. qui concernent l'histoire dc Bclgique. Bruselas, 1875.

(99) Collection de Memoires relatifs a l'histoire de Belgique. Ed., "Societé d'Hist. de Belgique", Bruselas, 1858-1874.

(100) Recueil des anciennes ordonances de la Belgique. Ed. "Comiss. royale des ancienes lois et ordonances de la Belgique", 1907.

(1.01) Paz: Inventaire des réquets privées du Conseil Supreme de Flandre et de Bourgogne. Bruselas, 1907.

(102) Feibve: Philippe II et la Franchc-Comté. París, 1912. 
guardan los fondos manuscritos de la Biblioteca Nacional (I0.3). En distintos lugares existen también valiosos elementos (IO4) y sería lástima que no acabásemos de emprender esta tarea.

\section{V.-LA LEGISLACION}

En otro orden, fuente esencial y fundamentalísima es la legislación. El examen de lo que sucede en Italia deja ver que no se trató de asimilar por el medio legal los nuevos territorios.

(103) Borrador original de la tralucción del italiano en romance de la desdripción de los Estados de Flandes por: Luis Guchardini, por Felipe. IV (ejemplar autógrafo). BN., Ms. 2.645, I, 35.

Cartas familiares de Don Antorio Solís a Don Alonso Camero sirviendo cn Flandes los puestos de Secretario de Estado y Gucrra y Vesdor General del. E'jérrito (1680), BN., Ms. 11.9117.

Consulta hecha por el Consejo de Estado de S. M., oponiéndose a las provisiones hechas de Gobcrnadores de las Provincias de Luxcmburgo u Namur, bN., Ms. 11.318-16.

Consultas del Consejo de Estado al Rey sobre asuntos de Flandes (1600), HN., Ms. 312.

Real Cédalla de Fclipe IV sobre propuesta de cargos eclesiásticos, BN., Ms. 1861-20.

- de Felipe IV sobre competencia del Veedor y el Supcrintendente. BN., Ms. 18621-18.

Descripción de la tierra baxa o Flandes, BN., Ms. 5.770.

Despachos para S. M. del Gobierno de Flandes, BN., Ms. 9.888.

Discursos presentados al Archiduque Alberto sobre materias de Estado de Flandes (conveniencia de volver a la forma antigua de gobierno), BN., Ms., Varios, 2.346, f. 271 sig.

Discurso sobre el Gobierno de Flandes, BN., Ms. 1.009.

Escritos varios tocantes a la Monarchia de Sicilia, BN. Ms. 2.664-2.669.

Los antiguos Estados de Flandes en el siglo XVI, BN., Ms. 1.001.

Instrucciones que los Reyes de Espraña han dado a sus Virreyes y Gobernadores de Nápoles y Milán, BN.: Ms. 6.938.

- secretas para el Archiduque Alberto cuando fué a gobernar los Países Bajos (1595). BN., Ms. 10989-2.

Ordenanzas para los Tribunales y Hacienda de Flandes, BN., Ms. CC. 89.

Papeles varios sobre el gobierno y hacienda de Nápoles y noticia de sus virreyes, BN., Ms. 6.72.2.

Relación sustancial de lo que lua pasado sobre la tregua de Flandes, BN., Ms. 20.067-10.

Reflexiones y observaciones políticas sobre la pradmática cmanada debajo de la autoridad del Gobernador de Flandes (167.4). BN., Ms. 11.088, f. 181 sig.

Soneto burlesco describiendo a Flandes, BN., Ms. 3.922, f. 336.

I'ratados entre el Emperador Carlos $V$ y los Estados del Imperio tocante a las Provincias de Flandes (1548), BN., Ms. 10.819-33.

(104) Ponencia del Consejo de Castilla sobre Flandes, Ms. Instituto de Valencia de Don Juan, envío 38, núms. 8ij-88; Carta de Juan de Vega a Felipe II sobre el gobierno de Sicilia, Ms. Bibl. R. Mon. Escorial, II-7, fol. 279284 (Publ. en Papier's 'd'Etat du Cardenal Gravela, V, 142). Los fondos de Nápoles en Simancas son también muy valiosos, no hay que subrayarlo. Buen ejemplo el Catálogo XVI del Archivo General de Simancas, pub. por Ricardo MAGDaleno (Valladolid, 1943, Ediciones del Consejo Superior de Investiga892 ciones Científicas). 
Asi, en Sicilia, se utilizaron las instrucciones de Federico II al Almirante de su Imperio, etc. (105). Hay apenas una cierta relación entre las lcyes de la zona Sur; y Nápoles, Cerdeña y Sicilia, gozan de fuentes semejantes (106). Son tipicos, los Capitu'os de Cortes, que por el funcionamiento normal de este órgano representativo constituyen, como dice Del Giudize (I07), "la osamenta del derecho público del reino". El nombre de "Capitula", se da originariamente a la distribución de una serie legislativa, es decir, que con él se designa incluso la numeración material de las Constituciones aprobadas por el Parlamento, asimilándose al sistema de éstas por el uso común y judicial posterior (108). Otia fuente son las Sanciones, disposiciones derivadas cle la "iussio" virreinal. En Cerdeña predominan los Capitulos de Corte y las Pragmátias. I.os historiadores sardos reconocen a este respecto en Felipe II, el mérito de haber dictado muy útiles medidas para la administración de justicia, la instrucción pública y la economia agraria y comercial (iog). De esta misma atmósfera comprensivá y realista, es prueba la vigencia de algunas sanciones virreinales. El Bando del virrey Moncada de 23 de agosto de i $7 c 0$, fué aplizado hasta el presente siglo (IIO). Por otro iado hay que señalar la perduración de la legislación local. Por ejemp'o la famosa "Carta de logu" de Arborea, confirmada por Alfonso $V^{r}$, en cil Parlamento de I42I, es manten:da cxp!ícitamente por algunos territorios sardos (I I I.) En Nápoles destacan los capitulos y las pragmáticas, siendo de notar una cierta tendencia codificadora. Bajo Felipe IIT, el jurista Tapia redacta, en efccto, un Código filipino, que no llega a obtener sanción regia (1605-1643).

El sistema de fuentes varía en cl Norte de Italia, siendo funclamental en Lombardia la acción del Senado milanés. Este, creaclo por los franceses y mantenido por los españoles, ejerce función legislativa mediante sus Dccretos, que más tarde, se

(105) CF. Hnuiltann-Breouilles: Vie el correspondence de Pier de la Vijne. Parts, 1865, V. 597.

(106) Der. Giudice: Sinria del dirilto ilaliano, II, Fonti, Milán, 1923, p. 59. snhre Nápoles, y p. 6h, sohre Cerdeña.

(107) Det, Giudice:, o. c., p. 59.

(108) LA MaNTIA: Lordimamen/o, cit.

(IR.9) Der, Gitidice:. 0. r.. P. 65.

(110) Manno: Storia di Sardegna, II, p. 181.

(111) Pnr ej., Oristán. al inenrporarse a la Corona de Aragón en 1478. Sobre cllo BeNejto, Il dirillo calalano, cil. 
recopilan (II2). A su lado importa considerar las disposiciones dell Virrey, bandos o "gride", también recopiladas (I I3).

En cuanto a la legis!ación general es intcresante advertir la recepción de la "Constitutio carolina criminalis" dictada por Carlos V para Alemania en 1532 (I 3 ). Las Pragmátiças-sanciones toman especial vigor: son consecuencia de una decisión real sobre asunto abordado por su Consejo (I I4). Y, en fin, en el fondo rigen de manera supletoria y normal las leyes de la Corona aragonesa, que en algunos casos son recibidas explicitamente, como sucedió en la Baja Edad Media (I I5).

Mas confuso es el panorama de Flandes, que, sin duda! por su falta de tradición a! incorporarse (no se olvide que los Estados del Sur de Italia proceden de la vieja Corona de Aragón), se ven clominados. en el terreno legal, por un cierto cúmulo de Instrucciones, de Virreycs y de la Administración a pos Virreyes, por bajo cle las cuales asoman instituciones y parlamentos en acción. Que este problema clebió ser adverticlo por los políticos españoles, deja verlo e! propósito unificador señalado en la actividad carlina. Carlos, en efecto, va reuniendo orgánicamente los territorios buscando la sanción de la Dieta, como en I 548, o apovándose su régimen 'sucesorio, como en la Pragmática Sanción de I 549. No se pasa de ahí, sin embargo, y así ha podido preguntarse si intentó España asimilar aquellos territorios (I 6 ). Felipe II, cuya política recopiladora es conocida, trata, descle 1568 , de proyectar una sola legislación para todas aquellas provincias, mas parece que hubo de renunciar ante las dificultades de la empresa, que le eran presentadas por el Duque de Alba (i I7). Con todo, a Felipe se debe la reforma de la legislación penal, encomendada a ilos tres Consejos en 1570 , y realizada con las Ordenanzas penales de 5 y 7 de julio de aquel año, reforma muy elogiacla ( I I8).

$Y$ ya señalando la colaboración de los Consejos contestamos a otra pregunta: La de si aquella legislación dada bajio el domi-

(112) Ordinationes cxcellentissimus Senatus, Milán, 1743.

(113) C. Salvior.t: Storia del diritto italiane, $7:^{3}$ ed. p. 147.

(114) Así la definió Barrolo. In authentica de non alicnando, II, 1, 9. "Confirmalio facla a Principe cum consilio procerum."

(115) CF. BENEYTO, Il diritto catalano in Italia. "Riv. stor. dir. ital.",

VI, 1933, p. 431-433 (modo de expansión).

(116) Gossard: Espagnols et flamands, p. 307-309.

(117) "Col. doc. ined. hict. de Esp.", XXXVII, p. 8.t-85; LXX, p. 21.

894 (118) GosSARD, o.c., p. 309. 
nio español se ajusta a las necesidades del país o era arbitraria-. mente impuesta de manera teórica y absoluta. A van Kalken le llama la atención el caso de las Instrucciones, en donrle csta visión general es más explicable. Hay allí-dice (I I9)-expresiones estereotipadas, repetición de fórmulas idénticas, a menudo-sugiere-a despecho de las nuevas situaciones. Mas- $\mathrm{v}$ veamos cómo el punto polémico va subalveamente-se trata de medidas contra herejías, de quejas sobre la mala administración de la Hacienda... Añade que el derecho que el rey se reservaba de nombrar los oficiales de ciertas ciudades tomadas por los franceses (ejs. Arras y Saint-Omer, en 1659-1678), daba a este articulado el carácter de pretensiones "surannées". Pero ha de tenerse en cuenta que una ocupación militar ha de considerarse para el régimen político como situación interina y en todo caso ese texto significaba que el Rey no renunciaba a sus derechos (I 20).

Por otra parte hay que considerar que en el caso de las Instrucciones que no determinaban detalladamente la norma de resolución, no se trataba de alejamiento de la realidad, sino de tolerancia de un propio régimen administrativo. La subsistencia de la "consuetudo", y el mantenimiento del "regnum", señalan la presencia del sistema jurídico anterior. $Y$ a ello acaso haya que relacionar el testimonio que trae Guicciardini sobre la analogia entre la organización de Flandes y la francesa: "Hor qui discorreremo del governo e reggimento, che in questi paesi da sta parte $e$ in suo nome tiene il Principe conforme in sustantia, di magistrati di nomi e d'autoritá al governo e reggimento de Re di Francia ne! lor'Regno" (I2I).

\section{VI.-LAS INSTITUCIONES ITALIANAS}

Un examen de la Administrasión de aquellos territorios ha de quedar particularizado no sćlo con la distinción de Flandes e Italia, sino aún en la de propias zonas. Empezando por lo italiano hay que separar lo que tuvo anterior dependencia aragonesa de lo que constituye incorporación carlina. Tan fundamental resulta todo esto que, si en una y otra se mantienen "regnum" y "consuetudo", la vieja zona aragonesa conoce la insti-

(119) Van Kalken: La fin du regime, p. 61.

(120) VaN KaLkEN, o. c., p. 63-65.

(121) Gulcciardini: Descrittione, p. 47. 
tución incorporadora de la "communicatio", típica y de bien manifiesta efiacia. $Y$, en uno y otro caso hay que valorar los elementos nilitares, la situación y la función geopolítica. Asi, tanto en Cerdeña como en Milán, el factor estratégico tiene clara repercusión en su régimen administrativo.

Abcrdando la consideración de la zona aragonesa, el primer ejemplo nos lo da Cerdeña, donde continúa el régimen catalán establerido que, en virtud de la aplicación de la "communicatio". se inicia por obra del Privilegio "Coeterum", que traspasa los privilegios municipales de Barcelona con su "ius statuendi" - tan eficaz en el sistema de fuentes legales-, su ordenamiento judicial y su instituto del "mustazaf". Posteriormente importa la huella que deja la Ordenación de Pedro IV en el I355. Esta ordenación, estudiada por Era, señaló el propio regimiento sardo sobre la figura del Gobernador general, con un asesor, y cl régimen cle la hacienda (un administrador general, un procurador fiscal -y luego, en I480-un maestro racional), y de la justicia (un vicario, juez o veguer con un asesor) (122). Los oficialles quedan montados como en una burocracia, remunerados y con la titularidad de su puesto, nombraclos, revocables y sustituibles solamente por el Monarca, y sometidos a un estatuto de deberes clcterminado por una ordenanza propia. Prestaban juramento al ingresar y en tal ocasión podian quedar sometidos al cumplimiento de determinadas disposiciones, que asimismo juraban. Respondian de su gestión por medio del juicio de residencia - "parar" o "purgar taula", en la cxpresiva terminologia catalana. Más tarde, y siempre sobre cstas lineas, hay una clasifiación de funcionarios, y asi la pragmática de 1638 los distingue en mayores y menores ( 123 ). Entretanto con la mayor comfiejidad de la administración central han debido ir perdiendo fuerza las intervenciones de la Corona en la designación de los oficiales, y así se explica que un Privilegio a la Ciudad de Alguer on 1528, limite la posibilidad del nombramiento de funcionarios por el Gobcrnador (r24). Por lo demás se mantiene siempre la reserva de los oficios a los nativos (sardos, sicilianos, na-

(122) CF. Ena: L'ordinamento organico di Pictro d'Aragona per $i$ terrilori lel Cagliaritano. Sarer. 1933.

(123) Dixant: Capitula Regni Sardorum, III, 5, i. pr. El tema de la relación con los antecedentes frifericianos, que hacian de la designación de oficiales competencia exclusira del monarca y afirmahan su carácler intransmisiblr, en Kistronowicz, Kaiser Fricdrich der Zucilc, p. 214. 
politanos en cada territorio), y a los súbditos de los territorios metropolitanos de la Corona (catalanes, aragoneses, mallorquines $\mathrm{y}$ valencianos).

En la zona de Lombardia, incorporada con el Imperio carlino, se mantienen las instituciones, incluso las de más claro carácter poiitico, como el Senado, engranándose a la nueva administración sin que haya nada semejante a una nueva p'anta. En todo caso, estos territorios carecian de una tradición como la de Cerdeña y Sicilia, a los efectos del vínculo y el régimen, y rccibieron el doble influjo francés y caste!lano de la época.

Pormenorizando en esquema y en sintesis cada uno de los institutos sobre los que gira la Aclministración de Italia, aclvertimos en la cumbre el Consejo correspondiente. Con la unión de Castilla y Aragón bajo los Reyes Católicos, el antiguo régimen de la suprema administración italiana queda integrado en el Consejo de Aragón. Con Carlos V, se inician, en I 522 y a I .54.3, determinaclas reformas que culminan con la constitución del Consejo de Italia, separado del de Aragón desde I 555. Al nuevo organismo le corresponde la alta dirección aclministrativa y política cle los Virreinatos de Nápoles, Sicilia y Milán. Bien avanzada la Edad Moderna, Felipe V, unifica este Consejo con el de Castilla.

El Consejo de Italia, en su estructura teórica eseñiạl estaba constituído por el Vicecanciller, que era su jefe; el tesorero general, y cinco consejeros con títu!o de Regentes. Todos ellos sclian ser juristas. De este Consejo emanaban las órdenes que sancionaba el Rey. Era, además, órgano de comunicasión y de consulta; proponia cuantas decisiones consideraba interesantes y actuaba, finalmente, como tribunal supremo.

Entre tantas importantes materias la fundamental que al Consejo se ligaba era la propuesta de designación cle los Virreyes. A este respecto cxiste un curioso testimonio de lo que significaba su obra. Escribe Alberto Pecorelli (I25)-entre otras disposiciones del Conseio, no fucron las de menos prudencia cnviar a los Gobiernos de Italia al Condestable de Castilla en Milán, al Duque de Osuna, en Sicilia, y al Conde de Lemos en Nánoles, "porque según la naturaleza y las necesidades se ven las soluciones y ni a los plácidos lombardos se pedia mayor austeridad que la senil prudencia del referido Condestable, ni a la poco moderada licencia de la vivaz Sicilia menor, freno del treme-

(125) Aleterto Peconelli: Il Re Catholico, I, 9. Ed. Beneyto, p. 77. 
bundo Ducue' de Osuna, ni al decadente por no decir deprimido - reino de N!ápoles, menor sostén o ayuda que el circunspecto Conde de Lemos".

Realmente del virrey dependía el éxito de una política. $\mathrm{Pa}$ ra señalar la amplitud de sus poderes cita Eallesteros unas palabras del diploma de Carlos II a su virrey en Nápoles: "Os envío como otro yo a mi reino de Nápoles; os entrego toda jurisdicción, toda la autoridad y el poder de la espada" (I26). Y, áños antes, en 1571, el título de Gobernador de Milán a favor de don Luis de Requesens supone un "pleno et amplissimo mandato", durante tret años y en la repetida forma cle la alteridad: "et quae nos ipsi faceremus et facere possemus, si personaliter, ibidem adessemus" (127). Su antecedente, y realmente ya la institución, está en el Gobernador general, puesto de la Administración de los reinos de Levante conocido en Cataluña con este-nombre y con el de "Portant Veus". Jurídicamente es un ,Lugarteniente y se monta sobre las atribuciones que, consuetudinaria y constitucionalmente se atribuyen al Príncipe heredero durante las ausencias del rey. En Cerdeña se encuentra la institución desde I324 con el nombre de Gobernador general, y a partir del I4I5 con título de virrey. De esta fecha arranca asimismo el puesto de virrey de Sicilia, donde anteriormente se designaba como Lugarteniente; sin que falte ejemplo de llamarlo simplemente Embajador, sin duda porque venía a ser un enviado del Monarca.

El virrey recibía juramento de homenaje de los súbditos y a su vez juraba a éstos, en nombre del Rey, la observancia de la "consuetudo" o derecho establecido. Presidía la Real Audiencia y Parlamento y disponía de un sistema de órganos consultivos y de orobierno.

Bajo el dominio catalán-aragonés los virreyes son finos políticos que consiguen una insensitule incorporación. En la Edad Moderna se suelen enviar Grandes de España, protagonistas de historias galantes o Juristas alumnos del Colegio de Bolonia. Convendria puntualizar hasta qué punto estas dos procedencias intervinieron en la desartimulación administrativa que va asomando clurante este período ( 128 ).

(1?6) BAt.LESTERos: Historia de España ?l dc la civilizacionn. TV, 2, p. 30.

(127) Jubl. por cl P. Manch, El comendador maynr, p. 345-346.

(128) Snbre lo primero el anecdolario cs cxtensísimn, y va VillaunruTIA seinli el lípico caso del Duque de Medinaceli y la Criorgina.

De lo segundo puede dar un índice la sugerencia de Kavtonowvicz en lor898 r:o a la oposición Bólonia-Nápoles, Kaiscr Frićdrich der Zweitc, p. 124-125. 
Los órganos de gobierno y de consulta del virrey quedan establecidos según un esquema general. Entre los primeros figuraban la Real Audiencia en Sicilia y Cerdeña y el Consejo secreto de Milán y el cclateral de Nápo!es. Como órganos de consulta, el Parlamento y en su caso la Diputación permanente.

Cuenta la Vida de San Carlos de Orsenigo, qut el Gobernador de Milán disponía de una Consulta o Consejo secreto, de un Consejo general o Cancilleria y de varias altas autoridades, en primer lugar el Gran Canciller, secretario o asesor, y el Comandante del castillo o castellano. La Cancillería milanesa estaba constituída por sesenta miembros, diez por cada distrito o puerta de la ciudad, con nombre de decuriones. Pero el organismo más importante de la Administración de Lombardía es el Senado, integrado entonces por quince juristas con nombramiento vitalicio; de quien incluso dependía el Capitán de justicia, jefe de la policía ( I 29).

Justamente en Milán se entabla desde el primer momento una lucha entre el Gobernador y el Senado. Aquél va conquistando mavor autoridad a medicla que con el replanteo de cuestiones ante el rey éste toma decisiones favorables. Así queda ya fijado en las Instrucciones que Felipe II envía en I572 a don Luis de Requesens. Bien que más tarde se produzca una evolución, motivada por razones de efecto político, y las Instrucciones de io de diciembre de 1650 hablen de un uso moderado de la autoridad y de la petición de informes al Senado. El problema tuvo en Milán curiosas amplificaciones en relación con la Iglesia, especialmente tras el Concilio de Trento, con la famosa cuestión de la jurisdicción eclesiástica, en la que el Arzobispo consigue venzer la actitud del Senado (130). Mas clejemos estos aspectos episódicos para señalar el contorno jurídico de la institución.

Al lado del virrey encontramos en los territorios italianos un Conse io o Tribunal que puede quedar ejemplificado sobre la figura de la Real Audiencia, presiclida por el virrey y con el Regente de la Cancillería como jefe propio. Este, titulado desde la época de los Reyes Católicos, Asesor o Consultor (1487) es en todo

(129) C.F. P. MaRCII : El comendador mayor, p. 13؛-13's.

(130) El tema de la cuestión con el Arzobisno en MARCH: El comendadior. mayor. p. 186-3c.s. Cf. también el Pecreto del Gohernador Alburquerque, 25 agnsto 1569 , y recuérdese que la tregui iurisdiccinnal de 1615 es "provisional". Para conocer otros aspeztos es inleresante la aportación del P. SEnRANo: Correspondencia diplomítica cntre España y la Santa Sedc, Madrid, 1.914, III, p V-XL. 
momento cargo de la Magistratura, designado entre los jueces y siempre jurista de valor reconocido en su especialidad y con experiencia probada en materias de administración. La interven. ción cle cste elemento hace convertir en ciertas ocasiones el Consejo en instituzión técnica, y así en Nápoles precisamente una objeción que se hacía a la política española se referia a la colocación de consejeros "sabios y da:tos" que vigorizaban el poder del virrey (I 3 I ).

I os nombres de estos Consejos tienen modalidades regionales y dentro de su esquema caben sus matices. En Nápolles aparece la Gran Corte llamada Santa Concienzia con magistraclos cle designación bicnal. Felipe II crea el Tribunal del Consistorio sobre la base del de la Santa Conciencia y con tareas que le convierten en tribunal de garantias ciudadanas. Se mantiene, el antiguo Consejo de Santa Clara, con cinco miembros españoles y diez italianos, especie de Audiencia de la que dependian varios tribunales, entre ellos el de la Vicaría. A su lado se estab'ece, con mayor carácter palitico, el Consejo colateral o privado, verdadera "consulta" del virrey. Hay, pues, ahí una fuerte jerarquía administrativa, base de la situación territorial (I32).

El organismo más importante de toda aquella estructura es indudablemente el Senado milanés. Creado por Luis XII, fué reformado por Carlos V, privilegiado en 1527 y regido por in cstatuto fundamental. Según las disposiciones de Vormes los senadores eran de nombramiento real y tres de ellos naturales. Actuaban frente al Gobernador con propio poder, cle manera que suponia competencias superiores y exorbitantes a las de un simple órgano consultivo. Ocupado el Gobernador' en cuestiones militarcs, (Milán cierra el famoso cuadrilátero de las fortalezas ciel Norte de Italia: Pavía, Cremona, Como, Iodi, Novara, Tortona y Alejandría), se deja al Senado una acción específicamente política. Aunque el Gobernador designase los puestos de gobierno (podestá, vicario, capitán, juez), el Senado podía negar su ratificación y decretar, al cesar los titulares, el juicio de residencia. Así se comprende que las cuestiones entre el Senado y el Gobernador constituyan el cañamazo de la historia milanesa: buen ejemplo lo sucedido con Ferrante Gonzaga (I546-I555) y en fin las limitacio-

(131) Asi ln argumenta P. M. Doria en su Relazione, publ. "Arch. stor. prov. nap.". XXIV, 1899, ก. 56-(0).

900 (132) Bullesteros: Historia. TV, 2, p. 27-30. 
nes que establece Felipe II. Ya tras las Ordenanzas de Vormes de 1545, el Consejo secreto iba usurpando al Senado no sólo tareas políticas sino judiciales. Con la Ordenanza de Tomar, de I7 de abril de I $58 \mathrm{I}$, Felipe II reduce el derccho de interinación de las gracias a una simple formalidad cancilleresca de registro, sin otro valor que el de un parecer consultivo, estab!eciendo que en sus determinaciones el Senado se haya de someter a las leyes escritas y no pueda argüir utilizando el vago concepto de la equidad. Se cumplen así no ya una evolución típica de nuestra politica, sino actitudes que de igual modo se abren camino en Francia y aún en el Piamonte (I33).

Mas, en fin ¿cómo se explica siquiera el planteamiento de estas cuestiones en un órgano que debería aparecer subordinado al virrey? Hay que tener en cuenta que el Senado cuando fué establecido por' Luis XII estaba ligado no a la tradición ducal sino. a la parlamentaria francesa y por eso su evolución no pudo someterse a lo que resultaba lógico dentro de la conciencia juridica lombarda, a que era ajeno (r34). Así se produce la absorción de un poder regional, frente a la postura italiana que no daba otras garantías que las de los fueros o estatutos municipales. Sobre esta estirpe extranjera, actúan las influencias posteriores, dándola mayor complicación. Cuando Carlos V incorpora el Milanesado el Senado tenía dos elementos esenciales: uno, procedente de la reforma sforcesca, concreta las facultades politica y judicial y la función que se liga a la aplicación de la equidad; el otro, la interinación, de origen francés. Cuanto se clispone en Vormes $y$ en Tomar es radicalmente distinto y conduce a la frustración le aquellas actividades (135). Es preciso no olviclar que el Senado había recogido las consecuencias de la supresión de los Consejos secreto y de justicia (136). No poco hace, asimismo, una serie de reformas de carácter interno, principalmente sobre sus componentes.

Tras la reforma de $I^{\circ}$ de enero de 1.527 , decretada por Carlos de Borbón, capitán general de ios ejércitos españoles, el Senado se constituye con un presidente, cuatro caballeros y doce juristas. Dos años más tarde, Francisco Sforza, investido del Ducado por Carlos $\mathrm{V}$, hare algunas modificaciones, anuladas en

(133) Vianello: II senato, p. 56. "Arch. stor. lomb.", LXII, 1935.

(134) Vianelio, o. c., p. 6.

(135) Vianello, o. c., p. 8.

(136) Vianello, o. c., p. 13-19. 
1535 por el gobernador De Leyva. De esta época es la aprobación de una compilación de leyes, las llamadas "Nuove Costituzioni", preparadas por el Senado en cumplimiento de una orden dada en I534, y sancionadas por Carlos el 27 de agosto de I 54I. $Y$ ya no hay modificaciones interiores hasta 1622 , en que su presidente pasa a formar con otros miembros el Consejo secreto. Entre tanto, su composición ha ido sometiéndose a las vicisitudes de la política. Cuando el príncipe es nacional y residente aumenta el número de miembros cortesanos, prelados o caballeros: así en I 522 y I 530 ; cuando es extranjero y ausente aumenta la participación de los juristas, como en 1527 .

I.as competencias del Senado quedan fijadas por la Ordenanza de I 54I: consisten en la confirmación y abrogación de las disposiciones soberanas, la dispensa de fueros, la aprobación de cartas privilegiadas, las causas sobre feudos importantes, la segunda instancia en lo civil y lo penal. Contra su actuación judicial sólo cabe el recurso de reposición. Poco a poco ésta va siendo la definitiva, a medida que aumenta la beligerancia que se concede al Consejo secreto. Cuando se suprime la representación de los caballeros y está casi integrado de juristas, queda como alto tribunal con funciones políticas subrogantes (I37).

Los grandes oficiales sujetos al Gobernador o Virrey tienen su mejor símbolo en el Regente de la Cancillería, Asesor o Consultor, que no sólo era jefe cle la Audiencia, y, por lo tanto, de la Administración de justicia, sino verdadero juez de la ley. En efecto, el Virrey no podía adoptar medida alguna sin discutir previamente su oportunidad con los miembros de la Consulta o Audiencia. Entre ellos el Regente tenía una posición directiva poco común: dominaba cle tal manera que, en contra de lo que resultaba principio del sistema político al uso, era él quien exponía su opinión en primer término, de forma que los miembros se veían influídos por la misma. Por otro lado, el Regente debía suscribir las decisiones virreinales, afirmando de este modo su legalidad, bien que, como es claro, el valor legal solamente arrancaba de la sañión del Virrey. Así se ha podido considerar que mientras el Virrey es el "alter nos" del Soberano, el Regente cumple un papel semejante al de primer ministro. El arranque fundamental de su competencia no es, sin embargo, político, sino técnico, es clecir, justamente el clominio en el derecho, y tanto es así, que

(137) Vianello, O. c., p. 46. 
hay incluso pragmáticas que relacionan su intervención con el hecho de que los Virreyes fuesen gentes legas en materia forense $\left(13^{8}\right)$.

Acaso en Sizilia haya de enlazar esta principal figura al Grari Canciller de la ordenación fridericiana (r39), y en Cerdeña, montada la Real Audiencia al modo patrio, se liga a aquélla, como es lógico (I.40).

También tiene importancia bajo el dominio español la institución de los Parlamentos. Cuando existen con anterioridad, son mantenidos y se ligan al gran personaje que es el Regente de la Cancillería, asesores que presiden las Comisiones, en tanto el Virrey es cabeza del Pleno. Su origen y su desarrollo han de tener como previa introducción la exacta valoración de las circunstancias en que surgèn. Ya Marongiú ha hecho a este respecto un trabajo interesante (I4I), en el que sitúa los Parlamentos italianos en la línea europea y dentro de! sistema político de la Corona de Aragón. Subraya Marongiú el valor del Consejo Real en las regiones de infuıjo germánico y la significación de la representazión de las ciudades. En líneas generales, los Parlamentos italianos están constituídos por tres brazos: eclesiástico, real y militar; en algún caso son sólo dos: en Nápoles faĺta el militar, y, generalmente, dominan las ciudades gracias a la típica influencia de la capitadidad. La organización interna es semejante a la catalana. Hay fuero trienal. En Sicilia se aplica la Constitución "Una vegada al any", y funcionan los Memoriales de agravios, Diputación permanente, Secretaría, Comisiones... Las modalidades de precedencias, etc., apenas reflejan matices. Es interesante que mientras en Sicilia se sigue la norma de hacer hablar primero a los más dignos y a los más ancianos, Nápoles coloca en preferencia a los más jóvenes. El estudio que sobre Nápoles ha hecho la señorita Croce exalta el valor que se da a la concesión del subsidio en las convozatorias de 1283 y 1443 ; sus referencias al período $1507-1642$ quieren buscar ante todo ła causa de la decadencia de la institución (I42). El Parlamento napolita-

(133) P. S. LeIChT: Storia del diritlo pubblico italiano, Milán, 193\$, p. 332 .

(139) Sobre los grandes oficiales del reino normando. Schippa, o citada p. 66-67.

(140) Dei. Giudice, o. c., ค. 65.

(141) A. Marongin: I Parlamenti di Sardcrna. i. pr.

(142) Todo esto especialmenle en Elena CRnCE: I Parlamenti napoletani, Nápoles, 1937. 
no funciona bajo la presidencia de un Síndico, representante a la: vez de la capital y del reino. Hay dos estamentos: nobles (titulados o no) y ciudades reales. La situación de la capital es tan privi'egiada que de ella van a la Diputación permanente doce de los. veinticuatro micmbros que la constituyen. No creo que esto sea, contra Elena Croce, resultado de la centralización, sino consecuencia de la posición de superioridad que se atribuye a las capitales. La importancia de la Diputación permanente no tiene duda. Es el órgano más activo del Parlamento; preparaba los cuadernos de peticiones y discutía con el Virrey. Este, sin embargo, mantenía reciamente sus competencias y exclusivamente cuidaba amplias zonas, como la del abastecimiento, en la que se lleva una propia política, tendente, en línea general, a la prohibición de las exportaciones, contra el acaparamiento y contra la especulación (I43).

La organización local permanece. Hay jefatura del Podestá y órganos colegiales que corresponden a los Concelleres y a los Jurados de los reinos del Levante español.

\section{VII.-El regimen español en Flandes}

Al considerar la administración española de Flandes han de tenerse en cuenta el ambiente de la Corte borgoñona y aquellos aspectos que brillan en el Diszurso de Carlos, en Bruselas, al abdicar. Entraba por alli en elemento dinástico, y al establecerse una relación afectiva dire:ta, se tendió también a que por cl mismo camino andase la política. Carlos trató así de ampliar las facultades del Gobernador, pero también de facilitar la acción del del Poder central. Prueba expresiva es, a este respecto, la sustitución del Consejo privado, en I53I, por los tres: de Estado; de Hacienda y de Justicia.

También hay que considerar el formidable empuje económico de aquella zona, que cobra especial impulso en el siglo XVI sobre una base industrial, inicial y anterior (144). El capitalismo se constituye en relación con el funcionamiento del sistema de trabajo a domicilio y en el campo, dando origen a aquella plebe pobre y miserable, que nos testimonia en I557 el Embajador de Venecia, Bacloaro, y que plantea el famoso problema de la asistencia social, aquel "de subventione pauperum", que abre una

(143) Coniglo: Note sulla storia della politica annonaria, "Arch. stor. nap.", 1942. 
propia literatura, en la que, precisamente allí, destaza un español: Juan Luis Vives.

De ahí surge ya el primer tema: éste de la originalidad de los Decretos carlinos sobre asistencia pública.

Carlos V da, en efecto, un edicto, el 7 de octubre de 1531 , que significa, según Bonenfant (145), la primera tentativa del Poder central moderno para organizar de manera uniforme en aquellas provincias la asistencia a los menesterosos. Sus fundamentos son: $\mathrm{I}^{\circ}$, la prohibición absoluta de la mendicidad, y $2 .^{\circ}$, la centralización de los socorros. El F.dicto Hlega a mús: obligi is la asistencia escolar, debiendo acudir los niños a los centros de enseñanza o aprendizaje o servicio (I-16).

El Edicto nace a consecuencia de causas sociales. como la desorganización de la asistencia parroquial, que se mostraba con diferenciaciones evidentes y cluplic:dades de accesión; la abundancia de hombres sin trabajo, que vagaban como bandoleros, $y$, en fin, por la falta de educación rcligiosa y por el anabaptismo de fondo comunista. Hay, además, ideas en accióni. Y suena el nombre de Vives, que dedica a ila ciudad de Brujas, por aquellos años, un tratado doncle se exponen planes semejantes. Además, el Edisto imperial de I53I está precedido por ias Ordenanzas de Nurembeg ( 1522 ) e Yprés (1525). Nos movemos indiscutiblemente en un espacio donde corren doctrinas que tienden a influir en las instituciones públicas. La discusión sobre las fuentes del Edicto imperial y sobre el sentido de la Ordenanza de Yprés ha ocupado a varios autores (I47). Nolf, veladamente, y Winckelmann, con resolución, descartan la influencia directa de Vives, menos que por razones cronológicas porque la Ordenanza de Yprés es más radical que las texis del gran va'enciano, pero su influencia ha sido admitida tradicionalmente, habiendo sido proclamada de nuevo por Pirenne (148). También Pirenne habla de un cierto ambiente de erasmistas, juristas y capita-

(145) BONENFANT: Les origines et lc caractère de la réforme de la bienfaissance, "Rev. belge", V, 1926, p. 888.

(146) El texto en la ed. Lameene: Recueil des ordonnanccs dcs Pays-Bas, 2." ser., III, p. 265.

(147) Cf. Ehrle: Die Armenordnungen, "Ilist. Jahrb", 1888; WinckeLMANN: Ucber die aellesten Armenordungen, "Hist. Vierleljahrs", 1915, ע NOLF: La réforme de la bicnfaissance, Gante, 1915.

(148). Pirenne: Histoirc de Bclgiquc, III, p. 290. 
listas (149); ellos, sin duda, han propugnado la reforma, pero; como exactamente advierte Bonenfant ( 150 ), no han suministrado los elementos. Estos hay que ligarlos a la tradición intelectual de que Vives es primera figura, y acaso no sin contacto con actitudes análogas (I 5I). De cualquier modo importan: la nueva atmósfera, la obra del Rey y la opinión del humanista, anticipándose a cuanto llega a plantearse y sugerirse en España, donde no existe reglamentación hasta 1544 . Téngase bien en cuenta la actitud del Clero, que colabora, mientras los frailes combaten estas iniciativas (caso concreto, el de Yprés). Los conventos estaban frente a la prohibición de la mendicidad. En fin, el trabajo del P. Lorenzo de Villavicencio, De oeconomia sacra circa pauperum curam, se edita precisamente en Flandes, en Amberes, el I 564 .

La gobernación de aquellos territorios se dirige desde $\mathrm{Ma}$ drid, por el Consejo que asesora al Rey. El Consejo de Flandes. es creado por Felipe II en 7 enero I 588, con facultades consiliativas en materia de nombramientos, gracias y mercedes. La materia propiamente política no le compete, por ser atribuída al Consejo de Estado. Por lo demás, Felipe llevaba las cosas directamente, aunque se le llamase la atención por' el quebranto qur: producía a su salud. Las cartas extensas le eran resumidas, pero. siempre las apostillaba de su mano, rehuyendo que las resoluciones apareciesen en forma indeterminada (I 52 ).

En los Países Bajos el mando supremo lo tenía el Gobernador, verdadero "alter ego" del Monarca. Guicciardini dice' recogiendo la opinión de la época, que tenía tanta autoridad como. correspondía al propio Soberano (15.3). Para este puesto se solían designar personajes de la Nobleza ligados al Monarca y ajenos país. En Flandes, frecuentemente, fueron grandes señore: vecinos. Así, Gobernador Provinzial de Gueldres el Conde de. Nassau-Siegen; de Luxemburgo, el Conde de Autel, del Palatinado, etc.

Por bajo del Gobernador, los órganos de Gobierno, Conse-

(149) Pirenne, o. c., III. p. 289.

(150) Bonenfant, o. c. "Revue belge", VI, 1927, p. 211.

(151) BONENFANT, o. c., l. c.. VI, p. 224.

$(152)$ Sobre lo primero, Granvelaa: Papiers d'Elat y Lettres; Gachard: Rapport, p. L. Sobre lo segundo y precisamente enmendando a Antonio Pérez.

la redacción de una carla a Granvela, Gickind: Rapport, p. XLVIII. 
jos y el Secretario de Estado y Guerra; al lado, como órgano consultivo, los Estados generales.

Supervivencia de antiguos puestos, el Canciller de Borgoña (I54), a cuya desaparición cobra vuelo el Gobernador. Sucede esto con la muerte de Juan le Sauvage, en junio de I5I8. El título reaparece con cará:zter honorífico y asi vemos a tal Canciller presidiendo las Cortes de Valladolid, en I 523 (I 55).

De entre los Consejos, el antiguo, privado, da paso en I 53 I a los de Estado, Justicia y Hacienda. El primero surge de aquél, y los tres se ordenan como colaterales, según el reglamento carlino de 1532 ( 156 ). El Consejo de Estado (157) estaba compuesto de un número variable de miembros, designados por el príncipe, y generalmente Gobernadores provinciales y doctores. Su competencia es política: aconseja al Gobernador en lo referente al Derecho público, la paz y la guerra, el Gobierno general, los mandos militares, las fortificaciones. las Embajadas, etc. El Consejo de Justicia ( $5_{58}$ ) reúne a diez o doce caballeros y legistas que se ocupan de la administración juriscliccional, el Derecho, la policía, los privilegios, las gracias, los perdones, las leyes, los reglamentos, etc. Guicciardini le considera "riparo e baluardo della giusticia, per havere il supremo riguardo sopra tutte le cose". A este Consejo se asocian, como organismos colaboradores en sus propios territorios, el Consejo Supremo de Flandes, la Chancillería de Brabante y la Cámara de Holanda, que funcionan como nuestras Reales Audiencias. Y', finalmente, c! Conseio de Hacienda. dirigido por tres jefes: el tesorero, el resaudador general y varios prácticos, con la Cámara de Cuentas adscrita. Fué organismo que causa la aclmiración de Guiciardini y, según su fe. la de varios Príncipes extranjeros, que viendo alli tan bien ordenado el maneio de las rentas y. bienes, "han pediclo instrucciones para imitarlo" ( 159 ). ¡Hermoso testimonio de lo que llegó a hacer nuestra burocracia!

Intermerliario del Gohernador y los Consejeros era el Secretario de Estado y Guerra, verdadero "alter ego" de aquél y, como

(154) Sobre ins antecedentes de este puesto, H. Brestáu: Mandbuch der Urkiundenlehrc, Leipzin, 1912. I, n. 446.

(I5.5; C.r. Conres de León y de Castilla. IV, p. 353.

(156) Vas Katien, o. c.. p. 65.

(157) CiticciardiNi: Descrittinne, p. 49.

(158) Guicciardint, o. c., n., 50.

(159) Guicciardini, o. c., p. 51. 
el Regente de la Cancillería en Italia, auténtico primer minis. tro ( 160$)$.

No es, pues, una estructura que permita considerar desatendida por parte española la administración de aquellos territorios. Se ha dicho, sin embargo, que todo eso quedaba en el papel y que este hermoso aparato administrativo no funcionaba, Contrastaría con lo que dice Guicciardini; mas se afirma que los Consejos no se reunian bajo Fielipe II, sustituídos por una Junta de Gabinete. Si acaso algo de ésto pudiera haberse dado en años cn los que se jugaban intereses militares, anótese que ba jo el Gobierno de Margarita de Austria' y según Gossard (I6I), alguno de ellos "se reunía dos veses al día".

I.os Parlamentos funcionan como órgano consultivo con el nombre de Estados Generales. Reunidos por convocatoria del Rey o del Gobernador, celebran sus sesiones en Bruselas ge:teralmente, tanto porque alli reside la Corte como por respeto a los cle Brabante que no pueden deliberar según fuero, sino $\in \mathrm{en}$ su propio territorio. I os Estamentos son tres: el eclesiásticn, que acoge solamente a los abades, excluídos los demás por la exención; el noble y el de las tierras capitales. Por éstas acuden un burgomaestre o clos o tres escabinos o un funcionario de la ciudad. Brabante es la primera regivin y sus representantes pre ceden a los otros, como cabeza del reino.

El funcionamiento de los Estados generales tiene especiales características. Con motivo de la invasión francesa del Artés, en 4537, convocaclo urgentemente el Parlamento para el 24 de marzo en el Palacio de Bruselas ( I62), bajo la presidencia de la Regente, María de Hungria; del Cardenal Obispo de Lieja y de altos personajes; un miembro del Consejo privado pide, en nombre del Regente, el subsidio advirtiendo que la convosatoria no cra acostumbrada, y aun habla la misma Reina. Cada uno de los Estados se reúne para deliberar. Los de Brabante, adunados al siguiente día, se muestran conformes; mas los de Flandes ale gan !a necesidad de cambiar impresiones con sus mandatarios $\left({ }_{1} 6_{3}\right)$. Hácese asi, y de los cuatro principales miembros de este país, tres-Yprés, Brujas y Franco-se muestran dispuestos; cl cuarto, cuya cabeza es Grante, se opone, después de una

(160) Van Kalken: La fin du regimen. p. 67. cit. a Gaillard y De Breyne.

(161) GOSSARD: Espagnols et flamands. p. 307.

903 (16?) .J'STE: Lcs Pays-Bas sous Charles Quint, p. 80-83.

(163) JUSTE, O. c., p. 81. 
discusión interior, en la que los burgueses o rentistas se lanzan francamente en contra en representación de veintisiete distritos, en tanto que los artesanos, que reunían cincuenta y dos oficios, sacan a cuenta un viejo y discutido privilegio de María de Borgoña declarando que, siéndole preciso, servirian al Emperador con sus milicias y a sus propias expensas, pero no entregarian subsidio, opinión que, aprobada por la mayoría, es transmitida a la Regente. En fin, el 24 de abril se acepta el acuerdo de los Estados generales: tres de sus miembros pagan subsidio y uno aporta sus milicias. Llamados voluntarios a las armas, acuden bien y lealmente.

Hemos hablado ahí de la aplicación de un viejo privilegio de Maria de Bnrgoña. Se fecha en 1476 y se refiere a la exigencia de unanimidad en materia de impuestos, de forma que la mayoría no pueda obligar a la minoría ( 164 ). Hay que penetrar algo más en el estudio del episodio de I 5.37 para comprender las autonomías que se montaban sobre aquella base. En efecto, en aquel caso se huscaron fórmulas de mediación: la Regente propuso una rebaia del 50 por 100 en el subsidio, mas lo rechazaron los escabinos. Se trató de aue el Emperador resolviese. Además, y para evitar el mal ejemplo. se designó un tribunal arbitral formado por el nresidente del Consejo privado, un consejero y el Canciller del Toisón de Oro: este tribunal consideró ineficaz el privileçio de María de Borgnña e incluso se estimó anulado por un arto de r185. En fin. el Gran Conseio de Malinas y el Consejo privado entienden en el asunto, por deseo de los ganteses; llega a recurrirse al Emnerador. $v$ éste tiene aue intervenir por su Decretn de 31 de enero de $\mathbf{5} 5.38$, desde Bäcelona.

Por haio de los Estados generales existe una Administracińn nrovin-ial dirigida nor Conseios y Gobernadores. Además, cada región tiene peculiaridades propias en los órganos coleçiados. incluso en el nombre (Parlamento en Malinas, Cancillería en Brabante) v el número de lns consejeros (de seis a ocho), generalmente juristas. Sus nresidentes están dotados de una gran autnridad en materia de iusticia, con iurisdicción exclusiva en las alzadas v sobre los bienes fiscales. Del alto espíritu con que funcionaban estos organismos da muestra un ejemolo anortado por Guicciardini: "En Gueldres-dice (165)-, en tiempo del actual

Iring

(164) JUSTR, o. c., p. 83-85.

(165) Guicaiardini: Descrittione, p. 53. 
Rey Felipe, habiendo perdido éste una causa de importancia contra el Señor de Anholt, no hubo quien la quisiese ejecutar, y el Rey mismo ("¡oh justísimo Príncipe!-exclama el italiano-) !a hizo cumplir".

En las ciudades sigue asimismo el sistema de órganos colectivo asesor y unipersonal de gobierno. Las autoridades locales (burgomaestres y escabinos) son designadas en terna, a propuesta del Consejo municipal. Por lo demás, se mantiene la estructura anterior. Por bajo de ella, y de acuerdo con la importancia industrial de las zonas flamencas, funciona una organización gremial que interviene en ocasiones directamente en la Administración pública. Asi en el Municipio de Gante había tres Estamentos: el de los burgueses (rentistas y propietarios), los tejedores (en veintisiete grupos) y los artesanos (en cincuenta y dos gremios)-que vienen a corresponder a la levantina división en tres manos ("major", "menor" y "mijana) - Cada uno de estos grupos se reunía por separado cuando había que tomar cualquier decisión; su propuesta era of recida a la Asamblea y servía de base para una decisión general, llamada "collace"-nombre que asimismo designaba al conjunto de los estamentos (I66).

Con lo económico hay otro elemento que ha de considerarse al estudiar la Administración de estos países: lo militar. Quizá la mayor autonomía de su ordenamiento se enlace, como en el $\mathrm{Mi}$ lanesado, a la prioridad que se dió al aspecto estratégico. Así la significación de algunos territorios sirve para darles incluso un régimen de privilegio. Por ejemplo, Lieja, sometida a los vaivenes de la lucha entre Borgoña y Francia, tras el triunfo de la coalición granborgoñona, que hace arrasar la ciudad en 1482 , forma un sistema de imparcialidad en lla acción, garantía contra toda violencia, designada como "neutralidad" y reconocida en 1492 (I67). Mas desde I518, y por obra del Príncipe-Obispo Everardo de la Marca, forma con el Emperador.

Realmente aquellos territorios, viviendo en continuo pie de guerra, no ofrecen una institución específicamente militar propia. El título de Capitán General era honorífico. Cada Cuerpo

(166) Sobre Gante, BoRgUET: Insurrection des Gantois contre Charles Quint, Lieja, 1852, cit. por JusTE.

(167) Su base, la carta de neutralidad de Carlos VIII, 1492, y la declaración episcopal coincidente. Sobre todo ello, P. HARsin: Les origines di-

910 plomatiques de la neutralité liegeuse, "Rev. belge de phil. et d'hist.", V, 1926. 
de Ejército era mandado por el Gobernador de la provincia, sobre la unidad de la bandera, que más tarde da paso al regimiento (I68). Guicciardini decía que en tiempo de paz no había sino un millar de infantes para las fronteras y las fortalezas (i69); de caballería, unas seiscientas lanzas; de artillería, la Maestranza de Malinas. Y sobre su ordenación, unas viejas reglas, reformadas por Carlos V en 1547. Si existe un Almirante, apenas algunos pocos navios mal armados ( 170 ). En general, se requisaban buques en cada caso, abonando llos fletes. El Almirante gobierna las cosas de la mar, como jefe de la Armada, partícipe en las confiscaciones y el botín, asi como en las mercancías que por regio salvoconducto van o vienen de país enemigo.

La Hacienda se ordena por los enviados del Gobernador o Regente, que recorren el país, en revisión de cuentas, exenciones y abusos. Para lo militar hay dos contadurías.

Iunto a Flandes queda otro territorio: el Franco Condado o Alta Borgoña, al lado del Jura y con capital en Besanzón, antes en Dole. Carlos VIII de Francia lo entregó a Maximiliano I, esposo de María de Borgoña; aquél lo traspasa a su hijo Carlos V, de éste va a Felipe II, quedando incorporado a la Corona española. Ejemplo también muy interesante de la Administración de España. Sus habitantes defienden durante dos siglos la pertenencia española contra todos los intentos de ocupación hechos por Francia: en la guerra de los Treinta Años, bajo Richelieu, ante el Duque de Sajonia y frente a Luis XIV. Finalmente se entrega a Francia en I678, por el Tratado de Nimega (I7I). Su ordenación estatal no tiene problemas. Se mantiene el "regnum", como es norma, y rige su estructura anterior. A su cabeza hay un Gobernador no español, representante del Rey, y un Parlamento que vota el servicio o somete los agravios ( I 72 ).

\section{Juan Beneyto Perez Catedrático de Historia del Derecho}

(168) C.f. L. GOTHIER: L'organisation militaire de la municipalité de Liége au VXI e siécle. "Rev belge", XII, 1933. También VAN DER ESSEN: El ejército español en Flandes en el siglo XVI, anejo a la rev. "Haz", Madrid, 1943.

(169) GuIGCIARDI: Descrittione, p. 55.

(170) Guicciardini, o. c., p. 56.

(171) L. FEBVRE: Histoire de la Franche-Comte, Paris, 1912, y RodRiGUEZ VILl,a, cit. por Viñas: Imperio y Estado, "Rev. de la Univ. de Madrid", I, Letras, 1940.

(172) Gf. Ordenanzas de 1564, 1573 y 1586. 